\title{
Assessment of the Selective Properties and Optimization of Mesh Size of Pelagic Trawl Codends, Used for Fishing Mackerel (Trachurus Spp) in the Gulf of Guinea
}

\author{
Njomoue Pandong Achille*, Ebeku Ngomo Christopher, Tcham Leopold \\ Department of Fisheries, Faculty of Industrial Engineering, University of Douala, Douala, Cameroon \\ Email: "njopanac@hotmail.com
}

Received November 22, 2012; revised February 23, 2013; accepted March 6, 2013

Copyright (C) 2013 Njomoue Pandong Achille et al. This is an open access article distributed under the Creative Commons Attribution License, which permits unrestricted use, distribution, and reproduction in any medium, provided the original work is properly cited.

\begin{abstract}
Over the past few decades, it has become widely recognized that the management strategies of world fisheries must ensure sustainability of target species. The intervening years have seen many improvements to the concept of gear selectivity and methods for measuring the selectivity of fishing towed gears. Improved understanding of the principles of the selection of fish by gears has changed the list of parameters which are known to have a significant effect upon selection. The recent development of new mathematical models and the increased availability of powerful computers have resulted in improvements in the analysis procedures for the data produced to measure a gear's selectivity. The catch of mackerel in the gulf of Guinea has steeply declined during the last two decades, and resource management is clearly required. Therefore, the need for evaluation of trawl codends used in this fishery and the potential improvements to their selectivity are of prime importance. In this paper, we use semi-empirical models to define selective properties of pelagic trawl codends targeting black mackerel (Trachurus spp) in the Gulf of Guinea. These properties are determined using the experimental and theoretical methods of assessing the parameters of the selectivity curve, and by plotting the curve. Selection parameters were obtained by fitting a logistic equation using a maximum likelihood method. Trawl codend selectivity is estimated for 17 internal diamond mesh sizes in the range $47-79 \mathrm{~mm}$. Using the basic selectivity equations, we determine the needed mesh size $A=58 \mathrm{~mm}$ for fishing mackerel in the gulf of Guinea. This nominal mesh size gives room for $n_{j}=0.1$ catch of juveniles, which not exceeds the allowable proportion $\left[n_{j}\right]=0.1$. To provide resource conservation, there is the need to make amendments in the fishery regulations for more rational exploitation of mackerel stoks, because the currently use nominal mesh size $A=56 \mathrm{~mm}$ is rather unselective.
\end{abstract}

Keywords: Codend Selectivity; Mesh Size; Gulf of Guinea; Selectivity Models

\section{Introduction}

Trawling constitutes the principal fishing method of most Gulf of Guinea countries in general and Cameroon in particular. Some of the pelagic fish populations in the region have been heavily exploited and fishing effort may be above optimum levels for many species. One of the main target specie in Gulf of Guinea is black mackerel (Trachurus spp) [1]. However, in recent years a constant drop in catch has been observed due to a high intensity of trawl fishing. Consequently, the question of conserving the stocks of this species which constitutes a main source of food for most of the population of Gulf of Guinea countries is being put forward [2]. Such a ques-

\footnotetext{
"Corresponding author.
}

tion is often resolved in industrial fishing by way of a rational exploitation of fishable stocks. Rational exploitation has been examined by most scientists amongst who is R. J. H. Beverton, S. J. Holt, F. I. Baranov, M. Broadhurst, K. Matsushita, A. I. Trechev, V. N. Melnikov, A. V. Melnikov, D. A. Wileman, et al. Presently, different methods of regulating fishing are applicable: preventing, limiting and prohibiting methods. Technical regulations have been introduced in almost all developed fisheries worldwide during the last 30 years. The main objective of these regulations has been to improve the state of the fishery or the stocks within by allowing juveniles and young individuals to escape [3]. Much studies related to the selective properties of trawl codends have been carried out, until now, they are still being improved 
$[4,5]$. The selective properties of net codends are characterized by the selectivity curve $S(l)$ and its parameters-selectivity coefficient, selectivity range and the fraction of fish not subject to the selective action of the net [6]. In practice, different methods for studying the selective properties of trawl codends are used (covered codend method, alternate or parallel haul method, methods using special selective devices, etc.). The laboriousness of experimental studies on the selective properties of net codends as well as the difficulties linked with explaining the results make their use somehow difficult. The problem in using the covered codend method for example is that the cover might affect the fish escape process and hence bias results [7]. As a consequence of the complexity of the process of fish selection, theoretical research gives orientational assessment of the selective properties of net codends, while experimental, which are costly, are of partial character and do not explain many features of the selective action of trawl codends and, most important, it does not permit to establish well, exact and promising qualitative methods of regulating such properties [8].

In this work, the determination of the selective properties of trawl codends is based on the use of semiempirical models to evaluate the selectivity curve. These models facilitate a qualitative assessment of the character and degree of influence on the selectivity of the sizecomposition of the target fish shoal, the biometric characteristics of the fish morphology, deformation of the meshes, quantity of the catch etc. [9].

The process of removing fish from a water reservoir is selective and much attention is given to the regulation of fishing gear selectivity. Selectivity is estimated from the part of the gear where most fish escape. Recent research has shown that the selectivity of trawl fishing gears is highly dependent upon the mesh size from the codend [10]. Observations made by divers and towed underwater vehicles certainly show that large amounts of fish do escape in the codend and for most species this is where the main mesh selection is thought to occur [11]. Introduction of mesh regulations to reduce the catch of undersized target species constitutes a long-accepted management technique. Currently, the selectivity of a pelagic trawl is mainly regulated by the mesh size at the codend, reason for which the required selectivity of trawl codends is enhanced first of all, by choosing their mesh size. By way of varying the mesh size at the trawl codend, attempts are being made to regulate the size-composition of fish in the catch and control the degree of exploiting fish of different age groups, and consequently, formulate the most optimal size-age composition of the fish population remaining in the water-mass or reservoir [12].

Some methods employed to determine the mesh-size of net codends are known:

The experimental methods are of partial character, la- borious, do not give the generalities well $[13,14]$. Methods that use mesh size at the net codend equal to $60 \%$ $80 \%$ of gillnet mesh size $[15,16]$ give conflicting results because the working conditions and the characteristics of the gillnetting material and the codend netting are different. Instead, the methods using fish entanglement at the netting as a condition taking into consideration the biometric characteristics of the fish morphology to justify the mesh size are more justifiable [17]. However, they do not take into consideration the size composition of the targeted shoal, the indicators that regulate fishing, the varying fishing conditions etc. It is difficult to determine the mesh size alongside the coefficient of the allowable fishing mortality using the Baranov-Beverton-Holt equation and their modifications because of the difficulties associated with using the equation [18,19]. Methods based on determining the loss and gain in the transition from one mesh size to another [20] use not theoretical data in the calculations but statistical material, thus increasing the exactness of the results, though limiting its domain of use.

Considering the above mentioned shortcomings, this work takes into consideration the method that uses the basic selectivity equations [21] to determine the mesh size at trawl codends when fishing Atlantic black mackerel. Such equations without assumptions, link among themselves the size-composition of the target shoal of fish, the selectivity curves of the codend netting with mesh size, mature fish size, catch of juveniles, escapement of fish via the mesh. This means is more universal, exact, sticks with all other ways of determination of mesh size and can be associated to them.

Most of the countries of the Gulf of Guinea are less developed. They do not possess enough means to carry out laborious and costly experimental works to study the selective properties and the selectivity of trawl codends as a whole, and based on this reason, the selected methods are the most applicable in these countries.

\section{Materials and Methods}

Following semi-empirical models where used to assess the selectivity curve and its parameters. Selectivity gives where generated using the logistic function fitted to plots of the probability of capture against size.

$$
\begin{gathered}
S(l)=\frac{1-\alpha}{1+\exp \left[\frac{2.2 \cdot(K \cdot A-l)}{D}\right]}+\alpha \\
K=2 \cdot\left(\frac{1-\alpha\left(1+\frac{0.1}{K_{m}}\right)}{1-\alpha_{H C}}\right) \cdot\left(\frac{K_{c o r}(1-\varepsilon)}{K_{m} \cdot K_{c o r}}\right)
\end{gathered}
$$




$$
D=\frac{0.2 \cdot K_{c o r}(1+\varepsilon)}{(1-\alpha) \cdot K_{m}^{2} \cdot K_{c o m}} \cdot A
$$

where $S(l)$ is the function of the selectivity curve, $K$ is the selectivity coefficient, $D$ is the selectivity range, $A$ is the internal mesh size and $\alpha$ is the proportion of fish not affected by the selective effect of the mesh. $Q_{h}$ is the catch in tons per a tow of one hour duration. $K_{m}$ is the coefficient of the body of the fish, $K_{\text {com }}$ is the coefficient that takes into consideration the deformation of the body of the fish as it passes through the mesh, $K_{\text {cor }}$ is the coefficient that corresponds to the working shape of the mesh and the form of the mesh at the maximum cross section of fish's body. $\varepsilon_{m}$ is the relative work lengthening of the mesh. $l$ is the fish length; $A_{\min }$ and $A_{\max }$ are the mesh sizes, which correspond to the minimum and maximum length of fish in the size composition of the targeted shoals.

The determination of the mesh size of the trawl codends was based on the condition that, the quantity of juveniles $n_{j}$ does not exceed the allowable $\left[n_{i}\right]$. It is equally important to also know the relative quantity $n_{t}$ of mature fish that escape through the mesh codend. These characteristics of the selective action of trawl codends were determined using the following basic selectivity equations.

$$
\begin{gathered}
n_{e m}=\frac{y_{e m}}{y_{0}}=\frac{\int_{0}^{\infty} g(l) P(l) \mathrm{d} l}{\int_{0}^{\infty} g(l) S(l) \mathrm{d} l} \\
n_{p}=\alpha_{p}\left(\begin{array}{l}
\int_{0}^{\infty} g(l) S(l) \mathrm{d} l \\
n_{t}^{\infty} g(l) \mathrm{d} l
\end{array}\right) \\
N_{t}-Y_{t}=1-\frac{Y_{t}}{N_{t}}=1-\frac{\int_{j}^{\infty}}{N_{t}^{\infty} g(l) S(l) \mathrm{d} l} \\
n_{j}=\frac{Y_{j}}{Y_{0}}=\frac{\int_{0}^{\infty} g(l) S(l) \mathrm{d} l}{\int_{0}^{\infty} g(l) S(l) \mathrm{d} l}
\end{gathered}
$$

where $Y_{j}$ is the relative catch of juveniles, $Y_{t}$ is the relative catch of fish of mature size and $Y_{0}$ is the relative total catch $\left(Y_{0}=Y_{t}+Y_{j}\right) . \mathrm{N}_{\mathrm{t}}$ is the fraction of mature fish in the targeted shoals and $n_{e m}$ is the fraction of fishes entangled. $g(l)$ is the function of the distribution density of the size composition of the targeted shoals, $S(l)$ is the function of the selectivity curve of trawl codends and $P(l)$ represents the function of the codend entanglement capacity (function of the selectivity curve of gillnets), $l_{j}$ is the mature fish length and $\alpha_{p}$ is the ratio of fish that die against those that get out through the mesh.

The input data for determining the parameters and the function of the selectivity curve as well as the mesh size or dimension taking into consideration the allowable catch of juveniles are:

- Coefficient of fullness of fish's body $K_{m}$;

- Compression coefficient $K_{\text {com }}$ of fish's body as it goes out via the mesh;

- Coefficient of correspondence $K_{\text {cor }}$ between the working shape of the mesh and the maximum crosssectional area of the fish's body;

- $\quad$ Relative working lengthening of the mesh $\varepsilon_{m}$;

- Catch per hour of trawling $Q_{h}$;

- $\quad$ Minimum fish size in the targeted fish shoal $l \mathrm{~min}$;

- Maximum fish size in the targeted fish shoal $l$ max;

- $\quad$ Mature fish size $l_{j}$;

- Allowable catch of juveniles $\left[n_{j}\right]$;

- Allowable escape of mature fish through mesh of the trawl codend $\left[n_{t}\right]$;

- Seventeen internal mesh sizes whose selectivity curves cover the range of the size composition of fish in the targeted shoal;

- Variation series characterizing the size composition of the targeted shoal.

The value of the mature fish size $l_{j}$ and the allowable catch of juveniles $\left[n_{j}\right]$ are contained in the laws regulating fishing in the Gulf of Guinea [22].

The experimental fishing for the trawl codend selectivity was carried out on board the fishing trawler "Kelly Danielle" owned by the fishing company "Diamond Fish" from 2010 to 2011 in the Gulf of Guinea area with- in the territorial waters of Cameroon, Nigeria, Equatorial Guinea, Sao Tome and Principe and Gabon.

Experimental and statistical materials were obtained using the standard method [23]. The trawl codends were made from polyamide of different mesh sizes.

The input data used to determine the mesh size of the trawl codend were:

- Material for the trawl codend-Polyamide, $3.1 \mathrm{~mm}$ double twine;

- $\quad$ Trawling speed $v_{m p}=2.5 \mathrm{M} / \mathrm{s}$;

- Tow duration-1 hour;

- $\quad$ Average catch per one tow $Q_{h}=2$ tons;

- Allowable mature fish size by the legislation $l_{j}=$ 220 MM;

- Allowable catch of juveniles $\left[n_{j}\right]=0.1$;

- Allowable quantity of fish of mature size, that escape via the mesh $\left[n_{t}\right]=0.30$.

The initial data for the calculated size composition was given in the form of a variation series and inserted in Table 1. 
Taking into consideration the input data, the calculated parameters were determined and inserted in Table 2.

\section{Results}

For each variant of 17 mesh sizes, we obtained the parameters of the selective curve: The quantity $\alpha$ of fish not affected by the selective action of the mesh, the selectiveity coefficient $K$ and the selectivity range $D$ (Table 3). Results on catch parameters $Y_{0}, Y_{j}, Y_{t}, Y_{e m}$, are given in
Table 4 and the catch indicators $n_{j}, n_{t}, n_{e m}$ and $n_{p}$, in Table 5 .

Value of ordinates of selectivity curves for 13 fish sizes are given in Table 6.

\section{Discussion}

In this work, we use empirical models to define selective properties of a large range of diamond mesh codends of varying mesh sizes. In particular, the selective proper-

Table 1. Size composition of Mackerel.

\begin{tabular}{ccccccccccccccccc}
\hline li (mm) & 200 & 210 & 220 & 230 & 240 & 250 & 260 & 270 & 280 & 290 & 300 & 310 & 320 & $\Sigma m_{i}$ \\
mi & 4 & 12 & 20 & 51 & 38 & 29 & 15 & 12 & 7 & 4 & 2 & 0 & 4 & 198 \\
\hline
\end{tabular}

$\mathrm{li}=$ fish $\mathrm{size}, \mathrm{mi}=$ number of fishes

Table 2. Calculated parameters.

\begin{tabular}{|c|c|c|c|c|c|c|c|c|c|c|c|c|}
\hline$K_{m}$ & $K_{c o m}$ & $K_{c o r}$ & $\varepsilon_{m}$ & $Q_{h}$ & $l_{j}$ & $l_{\min }$ & $l_{\max }$ & {$\left[n_{j}\right]$} & {$\left[n_{t}\right]$} & $A_{\min }$ & $A_{\max }$ & $\Delta A$ \\
\hline 0.5 & 0.93 & 0.74 & 0.24 & 2 & 220 & 200 & 320 & 0.1 & 0.3 & 45 & 80 & 2 \\
\hline
\end{tabular}

$K_{m}=$ coefficient of fullness of fish's body, $K_{c o m}=$ compression coefficient of fish's body as it goes out via the mesh, $K_{c o r}=$ coefficient of correspondence between the working shape of the mesh and the maximum cross-sectional area of the fish's body, $\varepsilon_{m}=$ relative working lengthening of the mesh, $Q_{h}=$ catch in tons per hour of trawling, $l_{j}=$ mature fish size, $l_{\min }=$ minimum fish size in the targeted fish shoal, $l_{\max }=$ maximum fish size in the targeted fish shoal, $\left[n_{j}\right]=$ allowable catch of juveniles, $\left[n_{t}\right]=$ allowable escape of mature fish through mesh of the trawl codend, $A_{\text {ùin }}=$ minimum mesh size, $A_{\text {ùax }}=$ maximum mesh size, $\Delta A=$ step size.

Table 3. Selectivity curve parameters $\alpha, K$ and $D$ by mesh sizes $\left(A_{1}\right.$ to $\left.A_{17}\right)$.

\begin{tabular}{|c|c|c|c|c|}
\hline \multirow{2}{*}{\multicolumn{2}{|c|}{ Mesh size }} & \multicolumn{3}{|c|}{ Parameter } \\
\hline & & \multirow{2}{*}{$\begin{array}{c}\alpha \\
0.811\end{array}$} & \multirow{2}{*}{$\begin{array}{c}K \\
2.497\end{array}$} & \multirow{2}{*}{$\begin{array}{c}D \\
195.5\end{array}$} \\
\hline$A 1$ & 47 & & & \\
\hline$A 2$ & 49 & 0.669 & 3.452 & 116.4 \\
\hline$A 3$ & 51 & 0.562 & 3.91 & 91.58 \\
\hline$A 4$ & 53 & 0.481 & 3.761 & 80.44 \\
\hline$A 5$ & 55 & 0.421 & 3.995 & 74.77 \\
\hline$A 6$ & 57 & 0.376 & 4.048 & 71.86 \\
\hline$A 7$ & 59 & 0.342 & 4.083 & 70.53 \\
\hline$A 8$ & 61 & 0.316 & 4.107 & 70.19 \\
\hline$A 9$ & 63 & 0.297 & 4.123 & 70.51 \\
\hline$A 10$ & 65 & 0.282 & 4.135 & 71.28 \\
\hline$A 11$ & 67 & 0.271 & 4.144 & 72.38 \\
\hline$A 12$ & 69 & 0.263 & 4.151 & 73.71 \\
\hline$A 13$ & 71 & 0.257 & 4.155 & 75.22 \\
\hline$A 14$ & 73 & 0.253 & 4.159 & 76.87 \\
\hline$A 15$ & 75 & 0.249 & 4.161 & 78.61 \\
\hline$A 16$ & 77 & 0.247 & 4.163 & 80.43 \\
\hline$A 17$ & 79 & 0.245 & 4.165 & 82.3 \\
\hline
\end{tabular}

$\alpha=$ quantity of fish not affected by the selective action of the mesh, $K=$ selectivity coefficient, $D=$ selectivity range. 
Table 4. Catch parameters $Y_{0}, Y_{j}, Y_{t}$ and $Y_{e m}$ by mesh sizes $\left(A_{1}\right.$ to $\left.A_{17}\right)$.

\begin{tabular}{|c|c|c|c|c|c|}
\hline \multicolumn{2}{|c|}{ Mesh size } & \multicolumn{4}{|c|}{ Parameter } \\
\hline & & \multirow{2}{*}{$\begin{array}{c}Y_{0} \\
9.427\end{array}$} & \multirow{2}{*}{$\begin{array}{c}Y_{j} \\
1.154\end{array}$} & \multirow{2}{*}{$\begin{array}{c}Y_{t} \\
8.273\end{array}$} & \multirow{2}{*}{$\begin{array}{c}Y_{e m} \\
0.031\end{array}$} \\
\hline$A 1$ & 47 & & & & \\
\hline$A 2$ & 49 & 9.119 & 1.09 & 8.028 & 0.019 \\
\hline$A 3$ & 51 & 8.755 & 1.013 & 7.742 & 0.012 \\
\hline$A 4$ & 53 & 8.305 & 0.924 & 7.382 & 0.008 \\
\hline$A 5$ & 55 & 7.776 & 0.829 & 6.947 & 0.005 \\
\hline$A 6$ & 57 & 7.193 & 0.736 & 6.457 & 0.003 \\
\hline$A 7$ & 59 & 6.593 & 0.653 & 5.94 & 0.002 \\
\hline$A 8$ & 61 & 6.01 & 0.582 & 5.428 & 0.002 \\
\hline$A 9$ & 63 & 5.47 & 0.523 & 4.946 & 0.001 \\
\hline$A 10$ & 65 & 4.987 & 0.477 & 4.51 & 0.001 \\
\hline$A 11$ & 67 & 4.567 & 0.440 & 4.127 & 0.001 \\
\hline$A 12$ & 69 & 4.209 & 0.411 & 3.798 & 0.000 \\
\hline$A 13$ & 71 & 3.908 & 0.388 & 3.52 & 0.000 \\
\hline$A 14$ & 73 & 3.658 & 0.371 & 3.287 & 0.000 \\
\hline$A 15$ & 75 & 3.45 & 0.357 & 3.094 & 0.000 \\
\hline$A 16$ & 77 & 3.279 & 0.345 & 2.933 & 0.000 \\
\hline$A 17$ & 79 & 3.138 & 0.337 & 2.801 & 0.000 \\
\hline
\end{tabular}

$Y_{0}=$ relative total catch $\left(Y_{0}=Y_{t}+Y_{j}\right), Y_{j}=$ relative catch of juveniles, $Y_{t}=$ relative catch of fish of mature size, $Y_{e m}=$ relative quantity of entangled fishes.

Table 5. Catch indicators $n_{j}, n_{t}, n_{e m}$ and $n_{p}$ by mesh sizes $\left(A_{1}\right.$ to $\left.A_{17}\right)$.

\begin{tabular}{|c|c|c|c|c|c|}
\hline \multicolumn{2}{|c|}{ Mesh size } & \multicolumn{4}{|c|}{ Indicator } \\
\hline & & $n_{j}$ & $n_{t}$ & $n_{p}$ & $n_{e m}$ \\
\hline$A 1$ & 47 & 0.122 & 0.036 & -0.010 & 0.003 \\
\hline$A 2$ & 49 & 0.120 & 0.065 & -0.006 & 0.002 \\
\hline$A 3$ & 51 & 0.116 & 0.098 & -0.002 & 0.001 \\
\hline$A 4$ & 53 & 0.111 & 0.140 & 0.003 & 0.001 \\
\hline$A 5$ & 55 & 0.107 & 0.191 & 0.009 & 0.001 \\
\hline$A 6$ & 57 & 0.102 & 0.248 & 0.016 & 0.000 \\
\hline$A 7$ & 59 & 0.099 & 0.308 & 0.023 & 0.000 \\
\hline$A 8$ & 61 & 0.097 & 0.368 & 0.03 & 0.000 \\
\hline$A 9$ & 63 & 0.096 & 0.424 & 0.036 & 0.000 \\
\hline$A 10$ & 65 & 0.096 & 0.475 & 0.042 & 0.000 \\
\hline$A 11$ & 67 & 0.096 & 0.519 & 0.047 & 0.000 \\
\hline$A 12$ & 69 & 0.098 & 0.558 & 0.051 & 0.000 \\
\hline$A 13$ & 71 & 0.099 & 0.59 & 0.054 & 0.000 \\
\hline$A 14$ & 73 & 0.101 & 0.617 & 0.057 & 0.000 \\
\hline$A 15$ & 75 & 0.103 & 0.640 & 0.060 & 0.000 \\
\hline$A 16$ & 77 & 0.105 & 0.658 & 0.062 & 0.000 \\
\hline$A 17$ & 79 & 0.107 & 0.674 & 0.063 & 0.000 \\
\hline
\end{tabular}

$n_{j}=$ quantity of juveniles, $n_{t}=$ quantity of fish of mature size that escape via the mesh, $n_{p}=$ post selection mortality, $n_{e m}=$ quantity of entangled fishes. 
Table 6. Value of ordinates of the selectivity curve by mesh size.

\begin{tabular}{|c|c|c|c|c|c|c|c|c|c|c|c|c|c|c|}
\hline \multirow{2}{*}{\multicolumn{2}{|c|}{$\begin{array}{c}\text { Mesh } \\
\text { Size }(\mathrm{mm})\end{array}$}} & \multicolumn{13}{|c|}{$\operatorname{Sm}(l)$} \\
\hline & & \multirow{2}{*}{$\begin{array}{c}200 \\
0.946\end{array}$} & \multirow{2}{*}{$\frac{210}{0.951}$} & \multirow{2}{*}{$\frac{220}{0.955}$} & \multirow{2}{*}{$\begin{array}{c}230 \\
0.958\end{array}$} & \multirow{2}{*}{$\begin{array}{c}240 \\
0.962\end{array}$} & \multirow{2}{*}{$\begin{array}{c}250 \\
0.965\end{array}$} & \multirow{2}{*}{$\frac{260}{0.968}$} & \multirow{2}{*}{$\begin{array}{c}270 \\
0.971\end{array}$} & \multirow{2}{*}{$\begin{array}{c}280 \\
0.974\end{array}$} & \multirow{2}{*}{$\frac{290}{0.976}$} & \multirow{2}{*}{$\frac{300}{0.979}$} & \multirow{2}{*}{$\begin{array}{c}310 \\
0.981\end{array}$} & \multirow{2}{*}{$\frac{320}{0.982}$} \\
\hline$A 1$ & 47 & & & & & & & & & & & & & \\
\hline$A 2$ & 49 & 0.881 & 0.895 & 0.908 & 0.920 & 0.931 & 0.941 & 0.950 & 0.957 & 0.964 & 0.969 & 0.974 & 0.978 & 0.982 \\
\hline$A 3$ & 51 & 0.802 & 0.828 & 0.852 & 0.875 & 0.895 & 0.913 & 0.929 & 0.942 & 0.953 & 0.962 & 0.970 & 0.976 & 0.981 \\
\hline$A 4$ & 53 & 0.715 & 0.750 & 0.786 & 0.819 & 0.850 & 0.877 & 0.901 & 0.921 & 0.938 & 0.951 & 0.962 & 0.971 & 0.977 \\
\hline$A 5$ & 55 & 0.629 & 0.669 & 0.712 & 0.754 & 0.794 & 0.832 & 0.864 & 0.893 & 0.916 & 0.935 & 0.950 & 0.962 & 0.971 \\
\hline$A 6$ & 57 & 0.551 & 0.592 & 0.637 & 0.684 & 0.732 & 0.777 & 0.819 & 0.856 & 0.887 & 0.913 & 0.933 & 0.949 & 0.962 \\
\hline$A 7$ & 59 & 0.485 & 0.524 & 0.567 & 0.616 & 0.666 & 0.717 & 0.766 & 0.811 & 0.85 & 0.883 & 0.910 & 0.932 & 0.949 \\
\hline$A 8$ & 61 & 0.433 & 0.466 & 0.506 & 0.552 & 0.602 & 0.655 & 0.709 & 0.759 & 0.806 & 0.846 & 0.880 & 0.908 & 0.930 \\
\hline$A 9$ & 63 & 0.391 & 0.420 & 0.455 & 0.496 & 0.543 & 0.595 & 0.650 & 0.704 & 0.756 & 0.803 & 0.844 & 0.879 & 0.907 \\
\hline$A 10$ & 65 & 0.359 & 0.383 & 0.413 & 0.449 & 0.491 & 0.540 & 0.593 & 0.648 & 0.703 & 0.755 & 0.802 & 0.843 & 0.877 \\
\hline$A 11$ & 67 & 0.334 & 0.354 & 0.379 & 0.410 & 0.447 & 0.491 & 0.540 & 0.594 & 0.649 & 0.703 & 0.755 & 0.802 & 0.842 \\
\hline$A 12$ & 69 & 0.315 & 0.332 & 0.353 & 0.379 & 0.411 & 0.449 & 0.494 & 0.543 & 0.597 & 0.651 & 0.705 & 0.756 & 0.802 \\
\hline$A 13$ & 71 & 0.301 & 0.314 & 0.332 & 0.354 & 0.381 & 0.414 & 0.453 & 0.498 & 0.548 & 0.601 & 0.656 & 0.709 & 0.758 \\
\hline$A 14$ & 73 & 0.289 & 0.301 & 0.315 & 0.334 & 0.357 & 0.385 & 0.419 & 0.459 & 0.505 & 0.554 & 0.607 & 0.660 & 0.712 \\
\hline$A 15$ & 75 & 0.280 & 0.290 & 0.302 & 0.318 & 0.337 & 0.361 & 0.391 & 0.426 & 0.466 & 0.512 & 0.562 & 0.613 & 0.666 \\
\hline$A 16$ & 77 & 0.273 & 0.281 & 0.292 & 0.305 & 0.321 & 0.342 & 0.367 & 0.398 & 0.433 & 0.474 & 0.520 & 0.569 & 0.620 \\
\hline$A 17$ & 79 & 0.268 & 0.275 & 0.283 & 0.295 & 0.309 & 0.326 & 0.348 & 0.374 & 0.405 & 0.441 & 0.483 & 0.528 & 0.577 \\
\hline
\end{tabular}

ties of codends with mesh sizes in the range $47-79 \mathrm{~mm}$ and made from double braided PA twines of $3.1 \mathrm{~mm}$ thicknesses.

Many factors influence the selective properties of trawl codends. These could be biological or biometric, physic-technical, technical and exploitation [24]. In this work, we just need to examine the influence of the meshsize which is an easily modifiable technical factor, and which, according to many papers presented on this subject-matter, has the most significant influence on the selective properties of trawl codends [25]. In fact, increasing the mesh size causes a displacement of the curve toward the right (Figure 1).

Likewise, the mesh size also influences the selective parameters $K, D$ and $\alpha$.

For a mesh size of $47 \mathrm{~mm}, \alpha$ approches 1 (0.811) and all fish caught is retained at the codend, while a meshsize of $79 \mathrm{~mm}$, causes the value of $\alpha$ to get toward 0 (0.245), and all the catch might escape from the codend. The relationship between the mesh size $A$ and the parameter $\alpha$ is complex, and tends to take an exponential shape Figure 2. It depends more on the concrete values of $\alpha$. The increase in catch will result to the decrease of $\alpha$ and vice-versa. Generally, the larger the fish in the shoal, the more $g(l)$ influences the shape and the lay-out of the

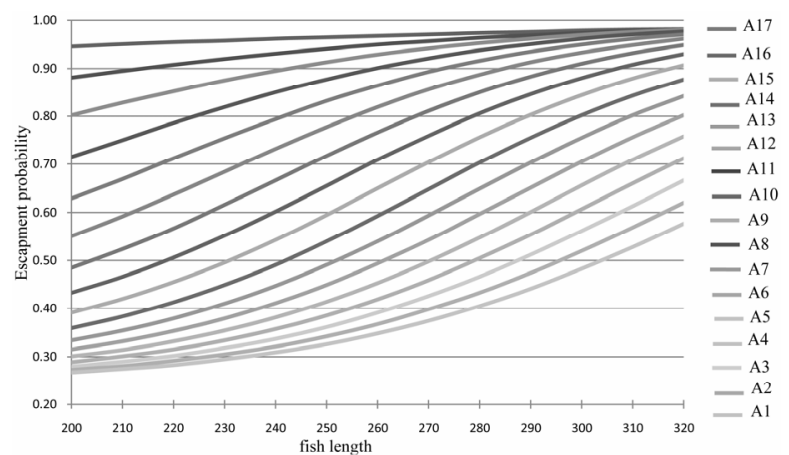

Figure 1. Family of selectivity curves for 17 mesh sizes $\left(A_{1}=\right.$ $49 \mathrm{~mm}$ to $A_{17}=79 \mathrm{~mm}$ ) when fishing Mackerel with pelagic trawls in the Gulf of Guinea.

curve $S(l)$. The relationship between the mesh size $A$ and the selectivity coefficient $K$ is shown in Figure 3. The selectivity coefficient $K$ rapidly increases as the meshsize $A$ increases until it attains a critical value (around $K$ $=4$ ), then it becomes practically constant. This mode of variation depends on the character of the influence of $\alpha$ on $K$. When the quantity of the capture inside the codend is low, the selectivity coefficient $K$ does not depend upon the mesh size. The selectivity range $D$, tends toward in finity for a mesh size that tends to retain or allow all the 


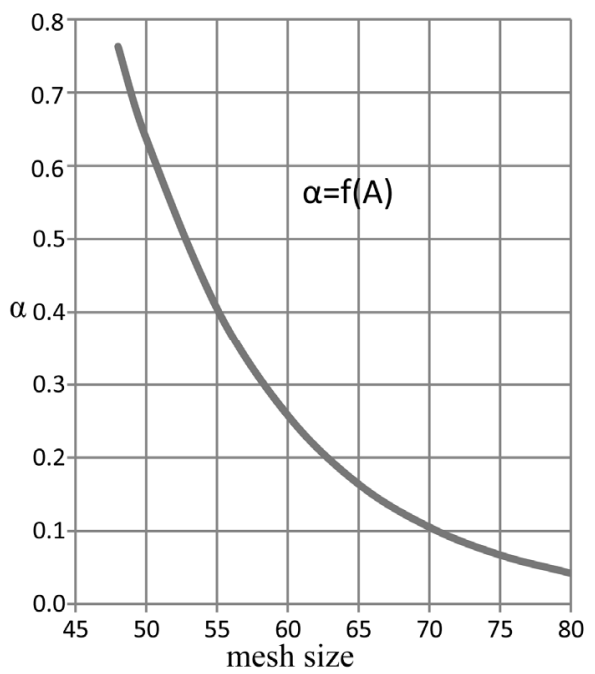

Figure 2. Relationship between the mesh size $A$ and the parameter $\alpha$.

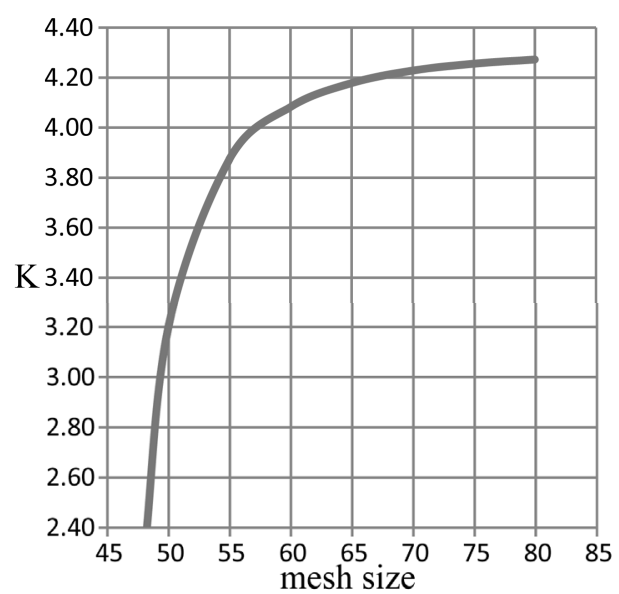

Figure 3. Relationship between the mesh size $A$ and the selectivity coefficient $K$.

fish to escape $(A=79 \mathrm{~mm} ; A=47 \mathrm{~mm})$, while the values of $D$ corresponding to intermediary mesh-sizes are minimal as presented in Figure 4.

The corresponding mesh-size for a variation in $\alpha$ close to 1 or to 0 also depends on the quality of the catch and on the size-composition of the target shoal $g(l)$ as represented in Figure 5. Furthermore, by using the basic selectivity equations for trawl codends, we have been able to provide the mesh size at the codend when fishing Mackerel in the Gulf of Guinea. Without assumptions, such curves are link the size-composition of the targeted shoal, the selectivity curve of a codend with a determined mesh size, mature fish size, catch of juveniles and the quantity of fish which escape from the codend. By using the basic selectivity equations, it is possible to determine mesh-size for different limitations in fishing. By solving the equation for different mesh sizes, it is also possible to draw the graphs $n_{j}=\mathrm{f}_{1}(A), n_{t}=\mathrm{f}_{2}(A), n_{e m}=\mathrm{f}_{3}(A)$ and $n_{p}$

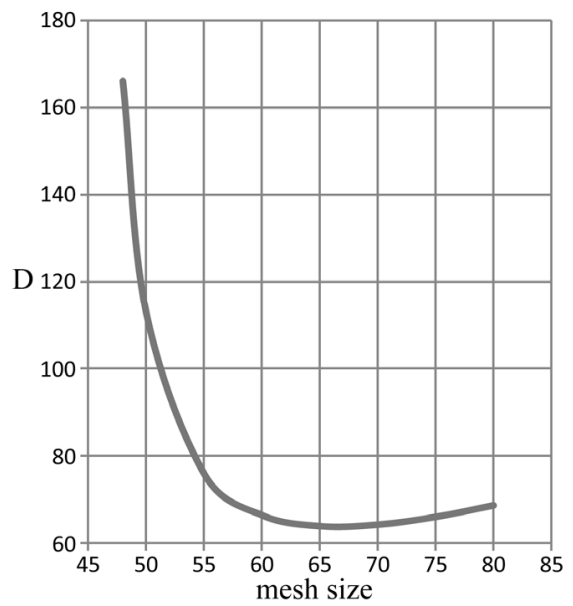

Figure 4. Relationship between the mesh size $A$ and the selectivity range $D$.

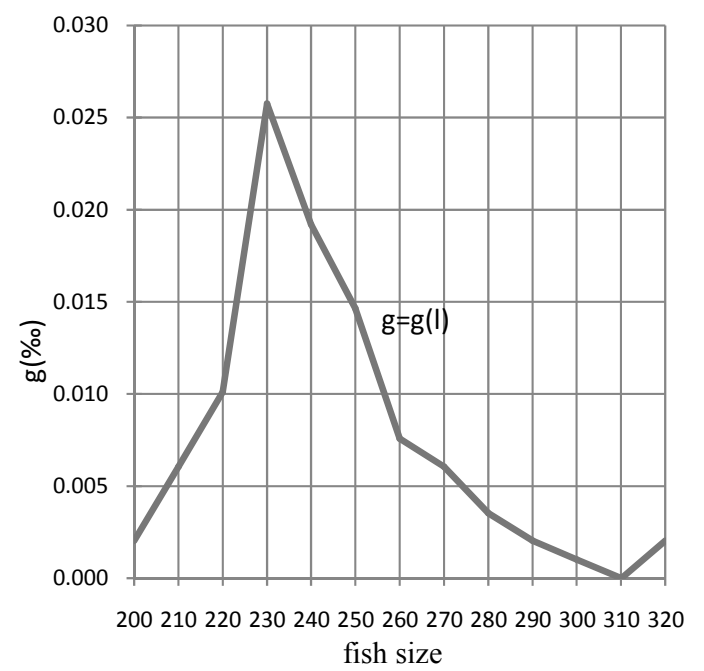

Figure 5. Density of size distribution of targeted shoals curve (\%).

$=\mathrm{f}_{4}(A)$.

In this work, such a justification is observed when the quantity of juveniles is limited as when as control is carried out for juveniles escaping via the meshes.

Using the data from the tables, we plotted graphs of functions $n_{j}=\mathrm{f}_{1}(A)$ and $n_{t}=\mathrm{f}_{2}(A)$ in one coordinate axes. By the curve $n_{j}=\mathrm{f}_{1}(A)$ and the given allowable catch of juveniles $\left[n_{j}\right]=0.1$, we determine the needed mesh size $A$ $=58 \mathrm{~mm}$ (Figure 6).

For this mesh size $A=58 \mathrm{~mm}, n_{j}=\left[n_{j}\right]=10 \%$ and $n_{t}=$ $28 \%$.

The escaping of mature fish at this mesh size was 0.28 and did not exceed the allowable $\left[n_{t}\right]=0.3$, while the estimated catch of juveniles $\left[n_{j}\right]=0.1$.

The selectivity curve corresponding to the optimal mesh size $A=58 \mathrm{~mm}$, is shown in Figure 7 .

In this case, the selectivity coefficient $K=4.31$ and the average inclination angle of the curve $\varphi=0.005$. 


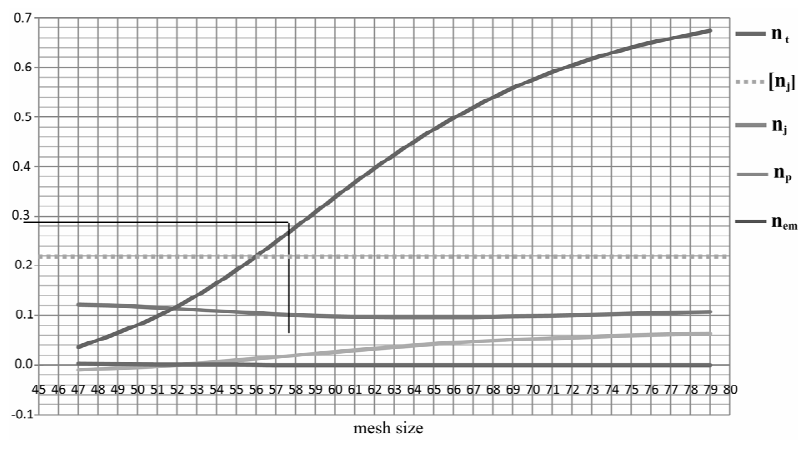

Figure 6. Dependence of selectivity indicators for catching Mackerel in the Gulf of Guinea with pelagic trawls on the mesh size of trawl codend.

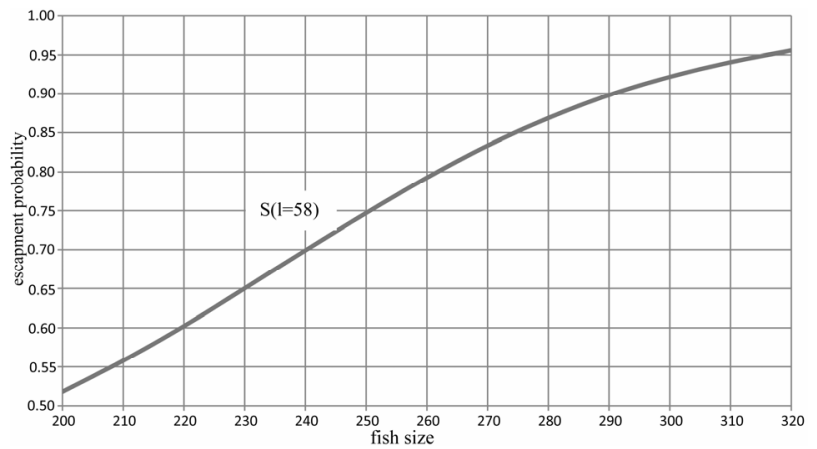

Figure 7. Selectivity curve corresponding of the optimal mesh size $A=58 \mathrm{~mm}$.

The above used models (4-7) are linked between themselves by the regulatory indicators $\left(l_{i}, n_{j} u A\right)$, the control indicator $\left(n_{t}\right)$ with the composition of the targeted shoal and the selectivity curve for the trawl codend. They do not contain assumptions and their exactness depends only on the exactitude of the initial data. The presented models will provide a better under standing of the selection process, permit a more targeted approach to codends selectivity experiments, and assist fishery managers to assess the impact of proposed technical measures that are introduced to reduce the catch of undersized fish. Currently, fishing regulations have adopted a mesh size of $A$ $=56 \mathrm{~mm}$ as the standard for codends of pelagic trawl gears fishing mackerel in the Gulf of Guinea [22]. This mesh size does not enhance the conservation of stocks of this specie because it gives room for a catch of juveniles $n_{j}=0.11$ which exceeds the allowable $\left[n_{j}\right]=0.10$, although it facilitates the escape of $n_{t}=0.22$ of mature fish, which is less than the allowable $\left[n_{t}\right]=0.3$. There is therefore the need to make amendments in the fishery regulations in the Gulf of Guinea for more rational exploitation of mackerel stocks.

\section{Acknowledgements}

We are grateful to the "DIAMOND FISH" Company for permitting us carry out the experimental work on- board the fishing trawler "Kelly Danielle".

\section{REFERENCES}

[1] FAO, "The State of World Fisheries and Aquaculture," FAO Fisheries and Aquaculture Department, Rome, 2009.

[2] P. N. Meke, "The Sustainable Management of the Marine Fish Resources in Cameroon: A Bioeconomic Analysis of the Trawl Fishery," Ph.D. Thesis, University of Douala, Douala, 2012.

[3] M. K. Broadhurst, R. B. Millar, S. J. Kennelly, W. G. Macbeth, D. J. Young and C. A. Gray, "Selectivity of Conventional Diamond and Novel Square Mesh Codends in an Australian Estuarine Peneid Trawl Fishery," Fisheries Research, Vol. 67, No. 2, 2004, pp. 183-194. doi:10.1016/j.fishres.2003.09.043

[4] R. B. Millar and R. J. Fryer, "Estimating the Size Selection Curves of Towed Gears, Traps, Nets, and Hooks," Review in Fish Biology and Fishery, Vol. 9, No. 1, 1999, pp. 89-116. doi:10.1023/A:1008838220001

[5] C. Kvamme and B. Isaksen, "Total Selectivity of a Commercial Cod Trawl with and without a Grid Mounted and Codend Selectivity of North-East Artic Cod," Fisheries Research, Vol. 68, No. 1-3, 2004, pp. 305-318. doi:10.1016/j.fishres.2003.11.011

[6] A. V. Melnikov and V. N. Melnikov, "Fishery Selectivity," ASTU, Astrakhan, 2005.

[7] P. G. He, "Selectivity of Large Mesh Trawl Codends in the Gulf of Maine: I Comparison of Square and Diamond Mesh," Fisheries Research, Vol. 83, No. 1, 2007, pp. 44 59. doi:10.1016/j.fishres.2006.08.019

[8] A. P. Njomoue, "Improvement of Pelagic Trawl Fishing in the Gulf of Guinea," Ph.D. Thesis, VNIRO, Moscow, 2002.

[9] A. V. Melnikov, "Calculation-Experimental Research Methods on Selective Properties and Justification of Mesh Size on the Concentrating Parts of Entangling Fishing Gears," Research on the Industrial Fishing Techniques, Collection of VNIRO Scientific Papers, 1983.

[10] R. P. Frandsen, N. Madsen and L. A. Krag, "Selectivity and Escapement of Five Commercial Fishery Species in Standard Square and Diamond-Mesh Codends," ICES Journal of Marine Science, Vol. 67, No. 8, 2010, pp. 1721-1731. doi:10.1093/icesjms/fsq050

[11] F. G. O'Neill and R. J. Kynoch, "The Effect of Cover Mesh Size and Codend Catch Size on Codend Selectivity," Fisheries Research, Vol. 28, No. 3, 1996, pp. 291303. doi:10.1016/0165-7836(96)00501-2

[12] A. I. Chevchenko, "Rational Trawl Fishing Technology of Pollock," Food Indutry, Moscow, 2004.

[13] D. A. Wileman, R. S. T. Ferro, R. Fonteyne and R. B. Millar, "Manuel of Methods of Measuring the Selectivity of Towed Gear," ICES Cooperative Research Report, Vol. 215, 1996, p. 126.

[14] A. I. Treshev, "Scientific Basis of Fishery Selectivity," Food Industry, Moscow, 1974.

[15] E. G. Norinov and E. Matsushita, "Selective Properties of Trawl Codends with the Covering of Square Structure," 
1998.

[16] F. L. Baranov, "Rational Fishing," Fisheries, No. 11, 1962, pp. 9-12.

[17] A. L. Fridman, "Theory and Projection of Fishing Gears," 2nd Edition, Food Industry, Moscow, 1981.

[18] Y. Matsushita, Y. Inoue, A. I. Shevchenko and Y. G. Norinov, "Selectivity in the Codend and in the Main Body of the Trawl," ICES Journal of Marine Science, Vol. 196, 1993, pp. 170-177.

[19] R. J. H. Beverton and S. J. Holt, "On the Dynamics of Exploited Fish Populations," Chapman and Hall, London, 1957.

[20] R. D. Galbraith, R. J. Fryer and K. M. S. Maitland, "Demersal Pair Trawls Codend Selectivity Models," Fisheries Research, Vol. 20, No. 1, 1994, pp. 13-27. doi:10.1016/0165-7836(94)90003-5

[21] A. V. Melnikov, "Determination of the Parameters of the Selectivity Curve Using Semi-Empirical Formulas," Collection of VNIRO Scientific Papers, 1985.
[22] CECAF/XIX, "Global Emerging Issues in Fisheries Development and Management Relevant to the Region," Cotonou, 2008.

[23] A. I. Treshev, C. F. Efanov, T. N. Stepanovich, et al. "Guidelines for the Collection of Data on the Selectivity of Trawls and Traumatic Death of Fish That Have Passed through the Mesh of the Trawl Codend," VNIRO, Moscow, 1983.

[24] F. G. O'Neill and B. Hermann "A Predictive Model of Codend Selectivity - A Tool for Fishery Managers," ICES Journal of Marine Science, Vol. 64, 2007, pp. 1558-1568. http://icesjms.oxfordjournals.org/content/64/8/1558.full.p df

[25] E. Grandcourt, T. Al Abdessalaam, S. Hartmann, F. Francis and A. Al Shamsi, "An Evaluation of the Selectivity Characteristic of Different Juvenile Fish Escape Panel Designs for the Demersal Trap Fishery in Abu Dhabi, United Arab Emirates," Open Journal of Marine Science, Vol. 1, No. 3, 2011, pp. 82-97. 